\title{
Population Carrying Capacity and Sustainable Agricultural Use of Land Resources in Caoxian County (North China)
}

\author{
Liming Ye \\ Eric Van Ranst
}

\begin{abstract}
In this study, an attempt is made to assess the potential sustainable agricultural use of the land resources in Caoxian County in north China. Based on a land resources inventory (physiography, climate, soil, land use and management), the rotation of winter wheat-summer maize was selected as the major land utilization type of grain production in the study area. Land use requirements were adapted to the local conditions and hierarchical production potentials were estimated using the collected data. Satisfactory results have been achieved for six scenarios combining local management practices and input levels. The population carrying capacity has been obtained and guidelines for a sustainable use of land resources were formulated. Conclusions were drawn with regard to the methodologies applied. [Article copies available for a fee from The Haworth Document Delivery Service: 1-800-HAWORTH. E-mail address: <getinfo@haworthpressinc.com>Website: <http://www.HaworthPress. com> (C) 2002 by The Haworth Press, Inc. All rights reserved.]
\end{abstract}

Liming Ye is Soil Scientist and Senior Researcher, Chinese Academy of Agricultural Sciences, Institute of Natural Resources and Regional Planning.

Eric Van Ranst is Full Professor and Director, Laboratory of Soil Science, Ghent University.

Address correspondence to: Liming Ye (E-mail: ye@ zadeh.rug.ac.be) or Eric Van Ranst (E-mail: eric.vanranst@rug.ac.be), Laboratory of Soil Science, Ghent University, Krijgslaan 281/S8, B-9000 Ghent, Belgium.

This study is part of the Belgium-China Project "Elaboration of Agro-Regional Development Models Based on a Sustainable Use of Land Resources in Different Zones of China" supported by the Flemish Interuniversity Council.

Journal of Sustainable Agriculture, Vol. 19(4) 2002

(c) 2002 by The Haworth Press, Inc. All rights reserved. 
KEYWORDS. Land evaluation, sustainability, population carrying capacity, land resources, production potential, China

\section{INTRODUCTION}

China is the world's largest developing country with a historical traditional agriculture. Wheat and maize, as main food crops, contributed greatly to the formation of the famous Chinese traditional agriculture. Since the Qin and Han dynasties, some 2,000 years ago, grain production has been the focus of Chinese agriculture, especially in the Yellow River basin (Ding Shengjun, 1988). Nevertheless, along with the industrialization and population growth in China, the fragile equilibrium between food demand and supply has caused extensive concerns from policymakers and strategists (Brown, 1995; Tang and Ye, 1995). Towards a sustainable agricultural use of land resources, either qualitative or quantitative aspects of the relationships among land productivity, food or grain production, population carrying capacity and land resource sustainability have to be examined. In this paper, an attempt is made to assess the population carrying capacity and the potential sustainable agricultural use of the land resources in Caoxian County in north China.

\section{MATERIALS}

\section{Physiography of the Study Area}

Caoxian County is located in the alluvial plain of the lower Yellow River in north China's Shandong province. It stretches from $115^{\circ} 0^{\prime}$ to $115^{\circ} 52^{\prime} \mathrm{E}$ and from $34^{\circ} 33^{\prime}$ to $35^{\circ} 0^{\prime} \mathrm{N}$, with a territory of $1,966 \mathrm{~km}^{2}$. The agricultural arable land accounts for 102,720 hectares $\left(1,027 \mathrm{~km}^{2}\right)$. Population was 1.16 million in 1995 (Caoxian Office of Statistics, 1995). The parent material of Caoxian soils is loess transported by the Yellow River from the Loess Plateau in the upper and middle reaches of the river. The county is located within the semi-arid temperate zone. The prevailing climate is the East Asian continental monsoon. Four seasons are distinctly differentiated. Annual sunshine hours account for 2,569.7, with an average sunshine percentage $(n / N)$ of 58. Multi-year mean of solar radiation is $513.0 \mathrm{KJ} \cdot \mathrm{cm}^{-2}$, and the photosynthesis active radiation $(P A R)$ is $223.2 \mathrm{KJ} \cdot \mathrm{cm}^{-2}$. Annual average temperature is 
$13.8^{\circ} \mathrm{C}$ with a daily difference of $10.6^{\circ} \mathrm{C}$. The frost-free period is 211 days (or 193 days when $\mathrm{P}=90 \%$ ), between March 29 and October 27. Statistics from a 28-year analysis reveal that the extreme temperatures do not impose a disastrous threat to crop cultivation. The multi-year annual precipitation mean is $686 \mathrm{~mm}$, ranging from $284 \mathrm{~mm}$ (in 1966) to $1,047 \mathrm{~mm}$ (in 1957), with a rainfall of $547 \mathrm{~mm}$ at $\mathrm{P}=80 \%$. The co-existence of precipitation and thermal resources facilitates the development of crops.

There are four groups of soils in Caoxian, namely aque-soils $(C)$, saline soils $(D)$, alkali soils $(E)$ and dust deposition soils $(I)$. They occupy $98.74 \%, 0.36 \%, 0.51 \%$ and $0.39 \%$ of the land surface, respectively (Table 1).

\section{Selected Land Utilization Type}

The land use in Caoxian is a combination of rainfed and irrigated agriculture, mainly of food crop plantations. In this context, the rotation cropping of winter wheat and summer maize during the same year has been selected as the land utilization type (LUT).

The crop cycles of winter wheat and summer maize take 248 and 100 days, respectively. Crop development stages $(C D S)$ are notified as $D i$ where $i$ is the serial number of the stage in concern (Tables 2 and 3).

TABLE 1. Soil classification: coding and list of families with distribution

\begin{tabular}{|c|c|c|c|c|c|c|c|}
\hline & \multirow{2}{*}{\multicolumn{2}{|c|}{ Code }} & \multirow{2}{*}{ Name } & \multirow{2}{*}{$\begin{array}{l}\text { Altitude } \\
\qquad(\mathrm{m})\end{array}$} & \multicolumn{3}{|c|}{ Distribution (\%) } \\
\hline & & & & & Family & Sub-group & Group \\
\hline \multirow{12}{*}{ C } & \multirow{3}{*}{$\mathrm{Ca}$} & Ca11 & Sandy cinnamonic aque-soils & 62 & 3 & \multirow{3}{*}{11} & \multirow{12}{*}{99} \\
\hline & & $\mathrm{Ca} 12$ & Silty cinnamonic aque-soils & 58 & 4 & & \\
\hline & & Ca13 & Clayey cinnamonic aque-soils & 60 & 4 & & \\
\hline & \multirow{4}{*}{$\mathrm{Cb}$} & Cb21 & Sandy auqe-soils & 54 & 45 & \multirow{4}{*}{66} & \\
\hline & & Cb22 & Silty aque-soils & 56 & 21 & & \\
\hline & & $\mathrm{Cb} 23$ & Clayey aque-soils & 49 & $<1$ & & \\
\hline & & Cb24 & Clayey deposition aque-soils & 59 & $<1$ & & \\
\hline & \multirow{3}{*}{ Cc } & Cc51 & Sandy saline aque-soils & 56 & 16 & \multirow{3}{*}{20} & \\
\hline & & Cc52 & Silty saline aque-soils & 57 & 4 & & \\
\hline & & Cc53 & Clayey saline aque-soils & 55 & $<1$ & & \\
\hline & \multirow{2}{*}{ Cd } & $\mathrm{Cd} 71$ & Sandy alkaline aque-soils & 60 & $<1$ & \multirow{2}{*}{$<1$} & \\
\hline & & $\mathrm{Cd} 72$ & Silty alkaline aque-soils & 53 & $<1$ & & \\
\hline
\end{tabular}

Source: Caoxian Regional Planning Office (1986a) 
TABLE 2. Crop development stages of summer maize in Caoxian (days)

\begin{tabular}{|c|c|c|c|c|c|c|}
\hline \multicolumn{2}{|c|}{ Bio-stage } & Sowing & Seedling & Jointing & Heading & Ripening \\
\hline \multicolumn{2}{|c|}{ Code } & D1 & $\mathrm{D} 2$ & D3 & D4 & D5 \\
\hline \multirow{4}{*}{$\begin{array}{l}\text { Rotating } \\
\text { with winter } \\
\text { wheat }\end{array}$} & Date & Jun-11 & Jun-21 & Jul-11 & Aug-11 & Sep-20 \\
\hline & \multirow{2}{*}{ CDS-days } & \multicolumn{2}{|c|}{10} & \multicolumn{2}{|c|}{30} & \\
\hline & & & \multicolumn{2}{|c|}{20} & \multicolumn{2}{|c|}{40} \\
\hline & Crop cycle & \multicolumn{5}{|c|}{100} \\
\hline \multirow{4}{*}{$\begin{array}{l}\text { Inter-cropping } \\
\text { with winter } \\
\text { wheat }\end{array}$} & Date & May-21 & Jun-01 & Jun-21 & Aug-01 & Sep-10 \\
\hline & \multirow{2}{*}{ CDS-days } & \multicolumn{2}{|c|}{10} & \multicolumn{2}{|c|}{40} & \\
\hline & & & \multicolumn{2}{|c|}{20} & \multicolumn{2}{|c|}{40} \\
\hline & Crop cycle & \multicolumn{5}{|c|}{110} \\
\hline
\end{tabular}

Source: Caoxian Regional Planning Office (1986b)

TABLE 3. CDS of winter wheat in Caoxian (days)

\begin{tabular}{|c|c|c|c|c|c|}
\hline Bio-stage & Code & Date & \multicolumn{2}{|c|}{ Stage length } & Crop cycle \\
\hline Sowing & D1 & Oct-01 & \multirow{2}{*}{7} & & \multirow{9}{*}{248} \\
\hline Seedling & D2 & Oct-08 & & \multirow{2}{*}{23} & \\
\hline Tillering & D3 & Oct-31 & \multirow{2}{*}{46} & & \\
\hline Dormant & D4 & Dec-16 & & \multirow{2}{*}{62} & \\
\hline Reviving & D5 & Feb-16 & \multirow{2}{*}{47} & & \\
\hline Jointing & D6 & Apr-04 & & \multirow{2}{*}{25} & \\
\hline Heading & D7 & Apr-29 & \multirow{2}{*}{7} & & \\
\hline Flowering & D8 & May-06 & & \multirow{2}{*}{31} & \\
\hline Ripening & D9 & Jun-05 & & & \\
\hline
\end{tabular}

Source: Caoxian Regional Planning Office (1986b)

There are only 15 days left for harvesting and sowing. The centuries long "dedicated" Chinese agriculture had proved that these two crops are fitting within one year, and the fieldwork is just a matter of technique and management.

\section{Land Use Requirements of Wheat and Maize}

Studies (Caoxian Regional Planning Office, 1986b) reveal that temperature, rainfall and radiation conditions are suitable for winter wheat and summer maize. Table 4 lists the climatic requirements and limitations of winter wheat as an example. 
Severe limitations are not found for topography, wetness, physical soil characteristics and fertility characteristics (Caoxian Regional Planning Office, 1986a). Table 5 summarizes the criteria used to classify local saline and alkali soils.

\section{METHODS}

The hierarchical production potential models of land evaluation, including the radiation-thermal crop production potential $(R P P)$, the water limited crop production potential (WPP) and the land production potential $(L P P)$, are applied in the study.

TABLE 4. Climatic requirements and limitations of winter wheat

\begin{tabular}{|c|c|c|c|c|c|c|c|c|c|c|}
\hline \multicolumn{2}{|c|}{ Development stages } & D1-D2 & D2-D3 & D3-D4 & D4-D5 & D5-D6 & D6-D7 & D7-D8 & D8-D9 & $\begin{array}{c}\text { Crop } \\
\text { cycle }\end{array}$ \\
\hline \multicolumn{2}{|c|}{ Days } & 7 & 23 & 46 & 62 & 47 & 25 & 7 & 31 & 248 \\
\hline \multirow{4}{*}{$\begin{array}{c}\Sigma T \\
\left({ }^{\circ} \mathrm{C}\right)\end{array}$} & Required & $\begin{array}{c}110- \\
120\end{array}$ & $\begin{array}{c}220- \\
260\end{array}$ & $\begin{array}{c}220- \\
320\end{array}$ & $\begin{array}{c}60-7 \\
0\end{array}$ & $\begin{array}{c}280- \\
320\end{array}$ & 340 & 120 & 650 & $\begin{array}{l}2,000- \\
2,200\end{array}$ \\
\cline { 2 - 12 } & Actual & 120 & 328 & 281 & 61 & 305 & 364 & 142 & 657 & 2,258 \\
\cline { 2 - 12 } & $+/-$ & +5 & +88 & +11 & -4 & +5 & +24 & +22 & +7 & +158 \\
\hline \multirow{3}{*}{$\begin{array}{c}\text { Water } \\
(\mathrm{mm})\end{array}$} & Required & 9 & 24 & 59 & 51 & 47 & 144 & 35 & 126 & 495 \\
\cline { 2 - 12 } & Actual & 12 & 24 & 29 & 19 & 32 & 42 & 9 & 46 & 212.5 \\
\cline { 2 - 12 } & $+/-$ & +3 & 0 & -30 & -32 & -15 & -102 & -26 & -80 & -282 \\
\hline \multirow{2}{*}{$\begin{array}{c}\text { Sunshine } \\
(\mathrm{h})\end{array}$} & Actual & 44 & 160 & 280 & 354 & 308 & 183 & 54 & 268 & 1,651 \\
\cline { 2 - 11 } & $\%$ & 2.7 & 9.7 & 16.9 & 21.5 & 18.6 & 11.1 & 3.3 & 16.2 & 100.0 \\
\hline
\end{tabular}

TABLE 5. Saline and alkali soils: classification criteria and distribution

\begin{tabular}{|c|c|c|c|c|c|}
\hline Soil Unit & $\begin{array}{c}E C^{*} \\
\left(\mathrm{mS} \cdot \mathrm{cm}^{-1}\right)\end{array}$ & $\begin{array}{c}\mathrm{ESP}^{*} \\
(\%)\end{array}$ & Classified As & $\begin{array}{c}\text { Distribution } \\
(\%)\end{array}$ & $\begin{array}{c}\text { Sum } \\
(\%)\end{array}$ \\
\hline Cc53 & $8>4$ & $0<15$ & saline & 0.04 & \multirow{4}{*}{0.47} \\
\hline $\mathrm{Cd} 72$ & $7>4$ & $0<15$ & saline & 0.07 & \\
\hline Da11 & $11>4$ & $0<15$ & saline & 0.3 & \\
\hline Da22 & $20>4$ & $0<15$ & saline & 0.06 & \\
\hline Cd71 & $27>4$ & $44>15$ & saline-sodic & 0.37 & \multirow{3}{*}{0.88} \\
\hline Ea11 & $12>4$ & $31>15$ & saline-sodic & 0.46 & \\
\hline Ea12 & $16>4$ & $30>15$ & saline-sodic & 0.05 & \\
\hline
\end{tabular}

* Threshold values of EC and ESP are $4 \mathrm{mS} \cdot \mathrm{cm}-1$ and $15 \%$, respectively (Van Ranst, 1997). 


\section{Determination of Growing Period}

The growing period has been defined following the FAO concept (Cocheme and Franquin, 1967; Kowal, 1978). FAO defines the growing period as a continuous period in the year during which the precipitation is greater than half the potential evapotranspiration plus a number of days required to evaporate an assumed $100 \mathrm{~mm}$ of soil water. A usual approach is to incorporate a temperature threshold value (generally $6.5^{\circ} \mathrm{C}$ ) into the water balance and to subtract the period with temperature below the threshold value from the water availability period.

\section{Radiation-Thermal Crop Production Potential (RPP)}

The radiation-thermal crop production potential is the maximum production that a high-yielding variety at a specific location can achieve under optimal conditions, i.e., being free of stresses of water, nutrients, pests and diseases, and on a constraint-free soil. The $R P P$ value is given by the following model:

$$
R P P=\frac{0.36 \mathrm{bgm} \cdot \mathrm{KLAI} \cdot \mathrm{Hi}}{(1 / L)+0.25 c t}
$$

where $b g m$ is the maximum gross biomass production rate; $K L A I$ the maximum growth rate ratio $\left(K L A I=0.35 L A I-0.03 L A I^{2}\right)$; Hi the harvest index; $L$ the length of crop cycle and $c t$ the respiration coefficient $\left[c t=c 30 \cdot\left(0.0044+0.0019 t+0.001 t^{2}\right)\right.$, where $t$ is the mean daily temperature and $c 30$ takes the value of 0.0108 for non-legumes or of 0.0283 for legumes].

The maximum gross biomass production rate can be calculated from the sum of the maximum gross biomass production rate on overcast days and the maximum gross biomass production rate on clear days:

$$
b g m=f \cdot b o+(1-f) \cdot b c
$$

where $f$ is the fraction of the daytime that the sky is overcast, $f=1-$ $n / N ; b o$ and $b c$ are function of latitude and time of the year. Their values can be found from tables (Van Ranst, 1991). But such values are only valid at light saturation $(\mathrm{Pm})$ of $20 \mathrm{~kg} \mathrm{CH}_{2} \mathrm{O} \cdot \mathrm{ha}^{-1} \cdot \mathrm{hr}^{-1}$. The following corrections have to be made when $P m$ is different from $20 \mathrm{~kg}$ $\mathrm{CH}_{2} \mathrm{O} \cdot \mathrm{ha}^{-1} \cdot \mathrm{hr}^{-1}$ : or 
$b g m=f \cdot b o \cdot(1+0.002 y)+(1-f) \cdot b c \cdot(1+0.005 y)$ when $P m>20[3-1]$

or

bgm $=f \cdot b o \cdot(1-0.025 y)+(1-f) \cdot b c \cdot(1-0.01 y) \quad$ when $P m<20 \quad[3-2]$

where $y$ is the difference (\%) to the value of $20 \mathrm{~kg} \mathrm{CH}_{2} \mathrm{O} \cdot \mathrm{ha}^{-1} \cdot \mathrm{hr}^{-1}$, i.e.: $y=(P m-20) \cdot 5$.

\section{Water Limited Crop Production Potential (WPP)}

$R P P$ will be reduced if water stress occurs in the crop cycle, since the crop cannot transpirate at its maximum rate. The yield reduction depends not only on the extent of the water deficit but on the crop sensitivity to the water deficit as well.

The anticipated rainfed yield can be calculated from the data on the relative evapotranspiration $(E T a / E T m)$ and $k y$, the yield response factor, and the potential irrigated yield $(R P P)$ :

$$
W P P=R P P \cdot\left[1-k y\left(1-\frac{E T a}{E T c}\right)\right]
$$

Values of the yield response factor, $k y$, can be found in literature (Doorenbos and Kassam, 1979). In the calculation procedures, the $k y$ values of different stages should be incorporated into the corresponding relative evapotranspiration deficit ratio. If the $k y$ value is only available for the whole crop cycle, it should be applied into the yield reduction ratio after the evapotranspiration deficit ratio has been summed.

The maximum crop evapotranspiration $\left(E T_{m}\right.$ or $\left.E T_{c}\right)$ is the maximum rate that a certain crop can evapotranspirate, whilst the reference evapotranspiration $\left(E T_{0}\right)$ is the maximum rate the reference crop (alfalfa or grass) can evapotranspirate. A classical two-step approach is applied in this study to calculate $E T_{m}$ by combining the values of the reference evapotranspiration $\left(E T_{0}\right)$ and of the crop coefficient $\left(k_{c}\right)$ in the following way:

$$
E T_{c}=E T_{m}=K_{c} \cdot E T_{0}
$$

The crop coefficient accounts for the effect of crop characteristics on crop water requirements: it relates the reference crop evapotranspiration $\left(E T_{0}\right)$ to the crop evapotranspiration $\left(E T_{c}\right)$ (Doorenbos and Pruitt, 1977). The crop coefficient is affected by crop characteristics, time of 
planting or sowing, stages of crop development and general conditions. Figure 1 shows the $K_{c}$ values of winter wheat and summer maize in Caoxian.

Actual evapotranspiration is the amount of water that is actually removed from the soil due to the processes of evaporation and transpiration. If the soil moisture, available for uptake by the plant through the root system, is adequate to meet the crop's demand, then the actual evapotranspiration of the crop $\left(E T_{a}\right)$ equals the maximum crop evapotranspiration $\left(E T_{m}\right)$ or the crop evapotranspiration $\left(E T_{c}\right)$; when the amount of available soil moisture is limited, $E T_{a}$ will be smaller than $E T_{m} . E T_{a}$ can be estimated through the application of the soil water depletion fraction $p$. Since evapotranspiration implies a decrease of the actually available soil moisture over the rooting depth per time unit:

$$
E t a=\frac{(S t . D)}{(1-p) S a \cdot D} \cdot E T c=-\frac{d(S t . D)}{d t}
$$

where St.D $<(1-p)$ Sa.D; Sa.D is the total available soil water over the root depth; St.D is the available soil water at time $t$ over the root depth; $p$ is the fraction of easily available soil water; $(1-p)$ is subsequently the fraction of scarcely available soil water. The above relationship can equally be written as:

FIGURE 1. Kc-curve of winter wheat and summer maize adapted to Caoxian conditions

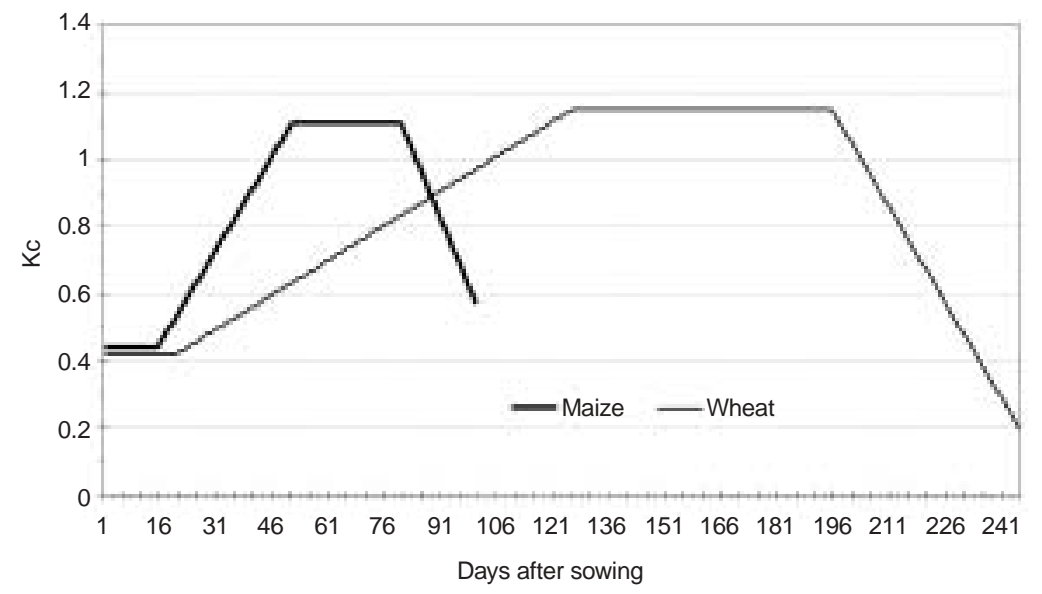




$$
E T a=S t . D-S t . D \cdot\left(e^{\frac{-E T c . t}{(1-p) S a . D}}\right)
$$

This is the expression for the actual evapotranspiration during the period of $t$ days $\left(\mathrm{mm}^{-p}\right.$ period $\left.^{-1}\right)$ after a fraction $(p)$ of the total available soil moisture $(S a)$ over the rooting depth $(D)$ has been depleted. The actual available soil moisture content at the beginning of the period is St.D and the potential crop evapotranspiration during the period is ETc. Figure 2 presents the relationship among available water capacity, the depletion factor, evapotranspiration and yield reduction.

\section{Land Production Potential (LPP)}

All soil parameters that have a direct impact on the performance of crops, not included in the calculation of water-limited crop production potential, have to be considered in the land production potential $(L P P)$. Such soil factors include: apparent cation exchange capacity $(A C E C)$, organic carbon $(O C)$ in the topsoil $(0-25 \mathrm{~cm}), p H$, electrical conductivity $(E C e)$, and exchangeable sodium percentage $(E S P)$.

FIGURE 2. Soil water availability, actual evapotranspiration and yield reduction

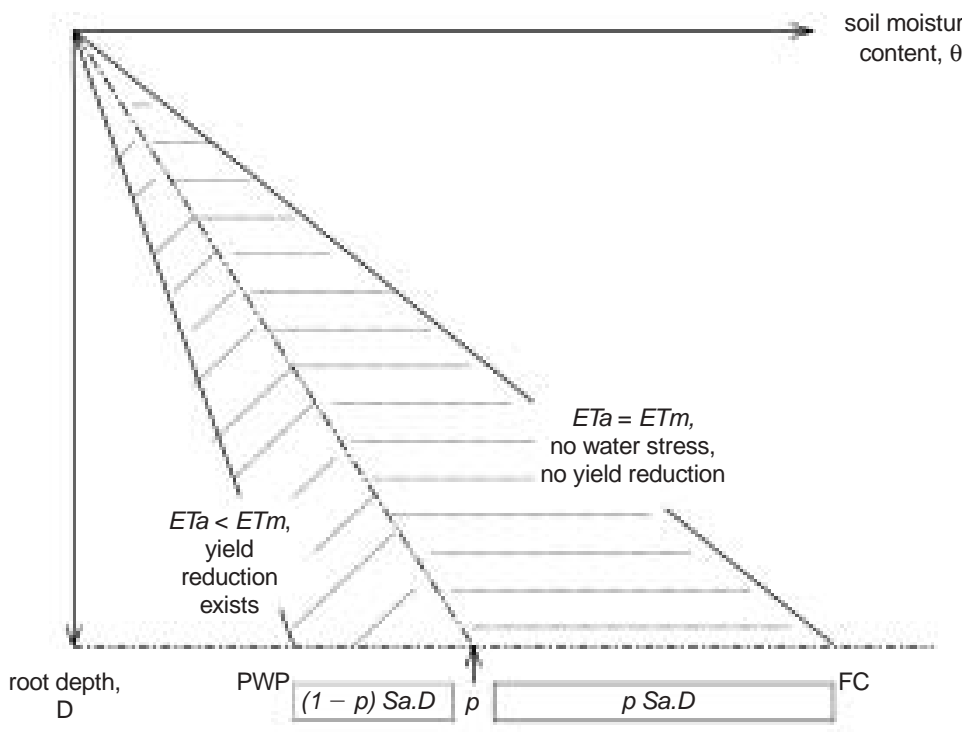


Numbered ratings attributed to these soil factors can be combined to a soil index, $S_{y}$, using the following formula:

$$
S_{y}=\frac{R(A C E C)}{100} \cdot \frac{R(O . C)}{100} \cdot \frac{R(p H)}{100} \cdot \frac{R(E C)}{100} \cdot \frac{R(E S P)}{100}
$$

Crop production is not only an interactive process of physical characteristics of the environment, such as energy, material, but an application of knowledge as well. Human activities play an impressive role in the sustainable development of the land productivity. Therefore, there must be a place for the management factor to be incorporated into the simulation of the crop production.

The management index, $M_{y}$, is difficult to determine. The human activities are closely related to the availability of capital. Thus it is a convenient way to correlate the management index to the level of inputs available to the crop production. In this study, 6 scenarios are designed to simulate different behavior patterns of the farmers: two management practices (rainfed or irrigation) by three input levels (high, medium and low).

$$
6(\text { scenarios })=2(\text { practices }) \times 3(\text { input levels })
$$

Combining the soil and management indices, the land production potential $(L P P)$ can be finally given by:

$$
L P P=W P P \times S_{y} \times M_{y}
$$

$L P P$ is an attempt to simulate the final yield achieved in the field. Therefore, it is necessary to keep in mind that $L P P$ is always related to the conditions assumed in different scenarios.

\section{RESULTS AND DISCUSSION}

\section{Radiation-Thermal Production Potential}

The crop cycle of winter wheat is 180 days (excluding 65 days of dormancy). During this period the leaf area index (LAI) at full crop development is $4.5 \mathrm{~m}^{2} \cdot \mathrm{m}^{-2}$. Maximum biomass production rate is $357 \mathrm{~kg}$ $\mathrm{CH}_{2} \mathrm{O} \cdot \mathrm{ha}^{-1} \cdot \mathrm{h}^{-1}$ and the total accumulated net biomass production is 
20 tons $\cdot \mathrm{ha}^{-1}$. Providing that $40 \%$ can be economically harvested, the yield is therefore 8.1 tons $\cdot \mathrm{ha}^{-1}$.

For summer maize, the maximum $L A I$ during 100 days of its crop cycle is $3.5 \mathrm{~m}^{2} \cdot \mathrm{m}^{-2}$. The maximum biomass production rate and the total accumulated net biomass production are $715 \mathrm{~kg} \mathrm{CH}_{2} \mathrm{O} \cdot \mathrm{ha}^{-1} \cdot \mathrm{h}^{-1}$ and 18 tons $\mathrm{ha}^{-1}$, respectively. The yield is 6.4 tons ${ }^{\cdot} \mathrm{ha}^{-1}$ when the harvest index takes a value of 0.35 .

\section{Water Limited Production Potential}

Since $E T_{a}$ evaluation is based on physical soil properties, WPP values in Table 6 are in accordance with soil units. Considerable reduction is observed for $W P P$ values.

\section{Landscape and Soil Constraints}

Summarized in Table 7 are major soil constraints for crop production and the overall soil index for pilot crops of wheat and maize in this study. A value of zero of the soil index simply implies unsuitability (i.e.,

TABLE 6. WPP determination (tons $\cdot \mathrm{ha}^{-1}$ )

\begin{tabular}{|c|c|c|}
\hline Soil & Wheat & Maize \\
\hline Ca11 & 3.1 & 5.9 \\
\hline Ca12 & 3.1 & 5.9 \\
\hline Ca13 & 3.4 & 6.4 \\
\hline Cb21 & 3.0 & 5.6 \\
\hline Cb22 & 3.0 & 5.7 \\
\hline Cb23 & 3.1 & 5.7 \\
\hline Cb24 & 3.1 & 5.9 \\
\hline Cc51 & 3.0 & 5.6 \\
\hline Cc52 & 3.1 & 5.9 \\
\hline Cc53 & 3.1 & 5.9 \\
\hline Cd71 & 3.0 & 5.6 \\
\hline Cd72 & 3.0 & 5.6 \\
\hline Da11 & 3.0 & 5.6 \\
\hline Da22 & 3.1 & 5.9 \\
\hline Ea11 & 3.1 & 5.9 \\
\hline Ea12 & 3.0 & 5.6 \\
\hline Ib11 & 2.9 & 4.8 \\
\hline Weighted mean & 3.0 & 5.7 \\
\hline RPP & 8.1 & 6.4 \\
\hline & & \\
\hline
\end{tabular}


TABLE 7. Major soil constraints and soil index $\left(S_{y}\right)$

\begin{tabular}{|c|c|c|c|}
\hline \multirow{2}{*}{ Soil } & \multirow{2}{*}{ Major constraints } & \multicolumn{2}{|c|}{$S_{y}$} \\
\cline { 3 - 4 } & & Wheat & Maize \\
\hline Ca11 & texture & 0.92 & 0.81 \\
\hline Ca12 & fertility & 0.81 & 0.82 \\
\hline Ca13 & fertility & 0.86 & 0.74 \\
\hline Cb21 & texture, o.c. & 0.73 & 0.73 \\
\hline Cb22 & texture, o.c. & 0.61 & 0.57 \\
\hline Cb23 & $\mathrm{pH}$ & 0.66 & 0.57 \\
\hline Cb24 & texture, o.c. & 0.7 & 0.83 \\
\hline Cc51 & texture & 0.79 & 0.66 \\
\hline Cc52 & pH & 0.73 & 0.64 \\
\hline Cc53 & salinity & 0.18 & 0.25 \\
\hline Cd71 & salinity, alkalinity, $\mathrm{pH}$ & 0 & 0 \\
\hline Cd72 & salinity, pH & 0 & 0 \\
\hline Da11 & salinity & 0 & 0.17 \\
\hline Da22 & salinity & 0 & 0 \\
\hline Ea11 & salinity, alkalinity, $\mathrm{pH}$ & 0 & 0 \\
\hline Ea12 & salinity, alkalinity, $\mathrm{pH}$ & 0 & 0 \\
\hline Ib11 & texture & 0.82 & 0.77 \\
\hline & & & \\
\hline
\end{tabular}

order " $N$ " in FAO land suitability classification) for the crop in concern.

Although not listed in Table 7, climatic factors are usual constraints to grain production, especially water availability in rainfed farming. Temperature sometimes becomes a limiting factor for a specific growing period, but not in general. In irrigated farming, much of the limitation related to water availability will be improved immediately and the suitability classes rise accordingly.

\section{Management Practices}

In rainfed agriculture, assumptions have been made that irrigation is very exceptional, and therefore $W P P$ best reflects the productivity before corrections are made for other soil constraints. In irrigated farming, major constraints coming from water shortage will be removed according to input levels and therefore the actual evapotranspiration will be increased and higher production will be achieved.

The input levels have been set as low, medium and high, and values of $0.6,0.8$ and 1.0 , respectively, have been designated to the manage- 
ment coefficient $\left(M_{y}\right)$, after examining agricultural economic conditions and farming behaviors of local farmers in Caoxian.

\section{Land Production Potential}

The first predicted production potential $(R P P)$ has been corrected for water availability, soil related factors and the socio-economic correlated management factors. All major factors that play a role in the energy, material and monetary circulations of the crop production process have been examined and included into the evaluation procedure. Therefore, $L P P$ is the most comparative estimate of the actual land productivity. Tables 8 and 9 present the $L P P$ results under different scenarios.

\section{Matching Predicted and Observed Yields}

Multi-year averages of yields from 10 out of 17 soil units in Caoxian have been collected based on a matching/overlaying inventory using

TABLE 8. Land production potential for rainfed farming (tons $\cdot \mathrm{ha}^{-1}$ )

\begin{tabular}{|c|c|c|c|c|c|c|}
\hline Soil & \multicolumn{2}{|c|}{ High input } & \multicolumn{2}{c|}{ Medium input } & \multicolumn{2}{c|}{ Low input } \\
\hline & Wheat & Maize & Wheat & Maize & Wheat & Maize \\
\hline Ca11 & 2.9 & 4.8 & 2.3 & 3.8 & 1.7 & 2.9 \\
\hline Ca12 & 2.5 & 4.8 & 2.0 & 3.9 & 1.5 & 2.9 \\
\hline Ca13 & 2.9 & 4.7 & 2.3 & 3.8 & 1.8 & 2.8 \\
\hline Cb21 & 2.2 & 4.1 & 1.8 & 3.3 & 1.3 & 2.5 \\
\hline Cb22 & 1.8 & 3.2 & 1.5 & 2.6 & 1.1 & 1.9 \\
\hline Cb23 & 2.0 & 3.2 & 1.6 & 2.6 & 1.2 & 1.9 \\
\hline Cb24 & 2.2 & 4.9 & 1.7 & 3.9 & 1.3 & 2.9 \\
\hline Cc51 & 2.4 & 3.7 & 1.9 & 3.0 & 1.4 & 2.2 \\
\hline Cc52 & 2.3 & 3.8 & 1.8 & 3.0 & 1.4 & 2.3 \\
\hline Cc53 & 0.6 & 1.5 & 0.4 & 1.2 & 0.3 & 0.9 \\
\hline Cd71 & 0.0 & 0.0 & 0.0 & 0.0 & 0.0 & 0.0 \\
\hline Cd72 & 0.0 & 0.0 & 0.0 & 0.0 & 0.0 & 0.0 \\
\hline Da11 & 0.0 & 1.0 & 0.0 & 0.8 & 0.0 & 0.6 \\
\hline Da22 & 0.0 & 0.0 & 0.0 & 0.0 & 0.0 & 0.0 \\
\hline Ea11 & 0.0 & 0.0 & 0.0 & 0.0 & 0.0 & 0.0 \\
\hline Ea12 & 0.0 & 0.0 & 0.0 & 0.0 & 0.0 & 0.0 \\
\hline Ib11 & 2.4 & 3.5 & 1.9 & 2.8 & 1.4 & 2.1 \\
\hline Weighted mean & 2.2 & 3.9 & 1.7 & 3.1 & 1.3 & 2.3 \\
\hline
\end{tabular}


TABLE 9. Land production potential for irrigated farming (tons $\cdot \mathrm{ha}^{-1}$ )

\begin{tabular}{|c|c|c|c|c|c|c|}
\hline Soil & \multicolumn{2}{|c|}{ High input } & \multicolumn{2}{c|}{ Medium input } & \multicolumn{2}{c|}{ Low input } \\
\hline & Wheat & Maize & Wheat & Maize & Wheat & Maize \\
\hline Ca11 & 7.5 & 5.2 & 6.0 & 4.1 & 4.5 & 3.1 \\
\hline Ca12 & 6.6 & 5.2 & 5.2 & 4.2 & 3.9 & 3.1 \\
\hline Ca13 & 7.0 & 4.7 & 5.6 & 3.8 & 4.2 & 2.8 \\
\hline Cb21 & 5.9 & 4.7 & 4.7 & 3.7 & 3.5 & 2.8 \\
\hline Cb22 & 4.9 & 3.6 & 4.0 & 2.9 & 3.0 & 2.2 \\
\hline Cb23 & 5.3 & 3.6 & 4.3 & 2.9 & 3.2 & 2.2 \\
\hline Cb24 & 5.7 & 5.3 & 4.5 & 4.2 & 3.4 & 3.2 \\
\hline Cc51 & 6.4 & 4.2 & 5.1 & 3.4 & 3.8 & 2.5 \\
\hline Cc52 & 5.9 & 4.1 & 4.7 & 3.3 & 3.5 & 2.5 \\
\hline Cc53 & 1.5 & 1.6 & 1.2 & 1.3 & 0.9 & 1.0 \\
\hline Cd71 & 0.0 & 0.0 & 0.0 & 0.0 & 0.0 & 0.0 \\
\hline Cd72 & 0.0 & 0.0 & 0.0 & 0.0 & 0.0 & 0.0 \\
\hline Da11 & 0.0 & 1.1 & 0.0 & 0.9 & 0.0 & 0.7 \\
\hline Da22 & 0.0 & 0.0 & 0.0 & 0.0 & 0.0 & 0.0 \\
\hline Ea11 & 0.0 & 0.0 & 0.0 & 0.0 & 0.0 & 0.0 \\
\hline Ea12 & 0.0 & 0.0 & 0.0 & 0.0 & 0.0 & 0.0 \\
\hline Ib11 & 6.6 & 4.6 & 5.3 & 3.7 & 4.0 & 2.8 \\
\hline Weighted mean & 5.8 & 4.3 & 4.7 & 3.5 & 3.5 & 2.6 \\
\hline
\end{tabular}

the GIS methodology applied. Village level yield data are well documented in the agricultural statistical yearbooks published by the local authorities. Table 10 lists a limited time series of area-wide yield data for the past 50 years. The above-mentioned 10 soil units take $98.3 \%$ of the land surface in the study area. Such observed yields reflect the total grain production on an annual basis. Considering that rotation of winter wheat and summer maize is fitting into one year in the study area (2-crops-1-year cropping), the comparison ground exists. Predicted yields of winter wheat and summer maize are drawn from the most common scenario of medium input and half rainfed by half irrigated lands. Table 11 summarizes the predicted and observed yields.

The combined yield of grains was 1.5 tons $\cdot \mathrm{ha}^{-1}$ during 1950-1970 in Caoxian. This figure increased to 3.5 tons $\cdot \mathrm{ha}^{-1}$ during $1970-1980$ but is still lower than the land production potential under rainfed farming with low input, which is 3.6 tons ${ }^{\cdot} \mathrm{ha}^{-1}$. However, the situation changed dramatically since the Chinese rural reforms in late 1970s. The combined grains yield reached 8 tons $\cdot \mathrm{ha}^{-1}$ during the period of $1980-1995$, which 
TABLE 10. Yield records of wheat and maize in a time series

\begin{tabular}{|c|c|c|c|c|c|c|}
\hline & \multicolumn{3}{|c|}{ Wheat } & \multicolumn{3}{|c|}{ Maize } \\
\hline & Sowing & Harvest & Yield & Sowing & Harvest & Yield \\
\hline Year & (ha) & (ton) & $\left(\mathrm{kg} \cdot \mathrm{ha}^{-1}\right)$ & (ha) & (ton) & $\left(\mathrm{kg} \cdot \mathrm{ha}^{-1}\right)$ \\
\hline 1950 & 55,267 & 24,621 & 446 & 7,867 & 3,186 & 405 \\
\hline 1955 & 76,467 & 61,422 & 803 & 11,867 & 6,987 & 589 \\
\hline 1960 & 60,867 & 37,935 & 623 & 3,267 & 2,808 & 860 \\
\hline 1965 & 42,333 & 28,099 & 664 & 7,933 & 9,336 & 1,177 \\
\hline 1970 & 44,867 & 34,525 & 770 & 9,333 & 16,660 & 1,785 \\
\hline 1975 & 48,467 & 67,975 & 1,403 & 15,400 & 35,921 & 2,333 \\
\hline 1980 & 49,000 & 104,003 & 2,123 & 15,600 & 38,493 & 2,468 \\
\hline 1984 & 67,067 & 249,488 & 3,720 & 9,000 & 34,560 & 3,840 \\
\hline 1992 & 72,201 & 306,891 & 4,251 & 21,373 & 113,692 & 5,319 \\
\hline 1993 & 77,185 & 342,210 & 4,434 & 32,636 & 153,017 & 4,689 \\
\hline 1994 & 71,823 & 355,314 & 4,947 & 30,592 & 146,688 & 4,795 \\
\hline 1995 & 76,334 & 355,377 & 4,656 & 39,380 & 215,760 & 5,479 \\
\hline
\end{tabular}

TABLE 11. Predicted and observed yields (tons $\cdot$ ha $^{-1}$ )

\begin{tabular}{|c|c|c|c|c|c|c|}
\hline \multirow{3}{*}{ Soil } & \multicolumn{5}{|c|}{ Predicted LPP } & \multirow{3}{*}{$\begin{array}{c}\text { Observed } \\
\text { yield }\end{array}$} \\
\hline & \multicolumn{2}{|c|}{$\mathrm{R}-\mathrm{M}^{*}$} & \multicolumn{2}{|c|}{$\mathrm{I}-\mathrm{M}^{*}$} & \multirow{2}{*}{$\begin{array}{l}\text { Sum } \\
\text { Grain }\end{array}$} & \\
\hline & Wheat & Maize & Wheat & Maize & & \\
\hline Ca11 & 2.3 & 3.8 & 6.0 & 4.1 & 8.1 & 7.8 \\
\hline Ca12 & 2.0 & 3.9 & 5.2 & 4.2 & 7.7 & 7.0 \\
\hline Ca13 & 2.3 & 3.8 & 5.6 & 3.8 & 7.7 & 7.3 \\
\hline $\mathrm{Cb} 21$ & 1.8 & 3.3 & 4.7 & 3.7 & 6.7 & 6.2 \\
\hline $\mathrm{Cb} 22$ & 1.5 & 2.6 & 4.0 & 2.9 & 5.5 & 6.0 \\
\hline $\mathrm{Cb} 23$ & 1.6 & 2.6 & 4.3 & 2.9 & 5.7 & 5.8 \\
\hline Cb24 & 1.7 & 3.9 & 4.5 & 4.2 & 7.2 & 6.7 \\
\hline Cc51 & 1.9 & 3.0 & 5.1 & 3.4 & 6.7 & 7.2 \\
\hline Cc52 & 1.8 & 3.0 & 4.7 & 3.3 & 6.4 & 5.7 \\
\hline Cc53 & 0.4 & 1.2 & 1.2 & 1.3 & 2.0 & 3.0 \\
\hline
\end{tabular}

${ }^{*} \mathrm{R}-\mathrm{M}$ = Rainfed farming with medium input; I-M = Irrigated farming with medium input.

is equivalent to the land production potential under irrigated farming with medium input. The current figure of combined grain yield was 10.1 tons $\cdot \mathrm{ha}^{-1}$ in 1997 , which already equals the $L P P$ of irrigated farming with high input. The potential to produce more food under the current technological conditions decreases accordingly. 


\section{Population Carrying Capacity}

The above analysis suggests that the grain production in Caoxian is nearly reaching its full potential. It is necessary to assess the population carrying capacity of the land resources in Caoxian by examining the grain consumption habits of the local people.

Studies (Ding Shengjun, 1988; CAS Study Group, 1989; Tang and Ye, 1995; Tang et al., 1997) concerning the quality of land resources, the consumption of grain products in China and the general conditions in which the Chinese economy is now growing, a quantity of $400 \mathrm{~kg}$ of grain was suggested to be the annual consumption level in the middle of the 1980s. It also recommended an alternative figure of 450 or 500 for 5 or 10 years, respectively, since then. Such figures were broadly applied later as the low, medium and high levels of grain consumption.

It has been clear that the productivity of 10 tons $\cdot \mathrm{ha}^{-1}$ of grain means: (1) irrigated farming system; (2) such system ensures $50 \%$ of the arable land under irrigation; and (3) a high level of input. Such conditions are feasible in Caoxian County. The irrigated land surface accounted for $65 \%$ of all the sowing area in 1997. A high level of input is not always possible since it involves the rate of return of the capital inputs, the expectation of the harvest and the individual willingness. However, a medium input level can be assumed and the capital agricultural goods are getting relatively more easily available as time progresses.

The scale of the grain production in Caoxian in recent years is at the level of 630,000 tons. Taking the criteria of per capita grain consumption of 400,450 and $500 \mathrm{~kg}$, the population carrying capacity is therefore estimated as 1.58 million, 1.40 million and 1.26 million, respectively. So, under the high level of grain consumption, the agricultural land resources in Caoxian can support 1.26 million people (equivalent to 640 people per $\mathrm{km}^{2}$ ), which is slightly more than the current population of 1.16 million (equivalent to 590 people per $\mathrm{km}^{2}$ ).

\section{Guidelines for Sustainable Use of Land Resources}

It has been realized that there are no fundamental deficiencies for agriculture to be a strong engine for economic growth as a whole (Schultz, 1964). However, it is only half done to merely transform the traditional agriculture into a highly proficient economic sector. Efforts have to be made to maintain the sustainability of land resources, the physical basis of agriculture (Ye and Tang, 1996). 
The soil resource with its various functions is of direct or indirect benefit to man and environment. Resilience has to be maintained for sustainable use. Sustainable land use refers to maintaining the three ecological functions of soils: (1) biomass production; (2) filtration, buffering and transformation of incoming materials and water; and (3) habitats for organisms, including people. It also refers to maintaining its suitability for three spatial attributes: (1) space for housing, industry, infrastructure, etc.; (2) space for extraction of mineral and other non-renewing resources; and (3) areas of cultural heritage. In a word, sustainable land use requires maintaining all land in a condition of usefulness, long-term productivity and ecological stability.

As claimed in Our Common Future (WCED, 1987), the ability of the land resources for future generations to meet their own needs cannot be compromised. Thus, concerning the current conditions in Caoxian, the following guidelines are suggested to lead to a sustainable use of the land resources.

Population control: Although grain production in Caoxian still meets the needs of the local people, it could be harmful to have an abnormal growth rate of population. Along the economic development process, it is quite clear that the proportion of the traditional agricultural sector will drop compared to the rise of other sectors like industries or even services. The need of arable land to be used for non-agricultural purposes will be high. There is already a tendency for the arable land to decrease in the past 10-20 years. Nevertheless, population control is not merely a precaution. It is a concrete measure in the sustainable use of agricultural lands in the long run.

Integrated management of the land resources: The management of land resources emphases not only on the waste of the land resources but also on the abuse of the land resources. FAO indicates that sustainable agricultural development is oriented to both technological and institutional changes. There is much work to do under this framework. For example, setting up a resource accounting mechanism would be very helpful to curb the improper use of land resources.

Appropriate technology: Modern agriculture is the fossil agriculture, which compromised the sustainable basis of the land resources. Application of large amounts of pesticides and herbicides not only endangers human life but also damages the resilience of the land resources. Sustainable agriculture is not limited to the context of ecological agriculture, but they share much in this concern.

Improvement of farming system: Caoxian agriculture is typically a traditional intensive farming system. The crop intensity index has been 
high for decades and the on-going rotation and inter-cropping farming practices are in the margin of the soil tolerance to maintain resilience. The majority of Caoxian soils are of a sandy texture, with difficulties in holding nutrients. A low content of organic matter is another threat to productivity on a sustainable basis. Since the population pressure is not as high as in other areas in southeast China, a rectification of the current farming system is urged to be studied and to be conducted. There exists a possibility of introducing a fallow rotation system into the local agriculture. Fallow could enhance the resilience of the soil base. All measures leading to an increase of the organic matter content in the soil are encouraged.

\section{CONCLUSIONS AND RECOMMENDATIONS}

The whole set of land evaluation methodologies applied is feasible and achieved satisfactory results in the data collected from the study area. Nevertheless, the methodology applied remains a guideline. Parameters, even estimated on the basis of the local conditions, are better than a blinding average value when the tested values of the parameters are not available. Inaccuracies of the results obtained in this study could result from the lack of detailed soil analytical data. Many soil-related parameters are estimated. Corrections made on the basis of broad information to the important crop parameters could also result in inaccuracies.

The selected land utilization type reflects the reality of grain production in Caoxain both in quantitative and in qualitative aspects. The predicted yields through different levels of production potentials fit into corresponding management conditions along tens of years in the past. The assumed scenarios reflect the management levels and work satisfactorily. A new way to manage the land resources on a sustainable basis is possible under current conditions. Measures can be taken to increase the resilience of the soil base of the land resources. Appropriate technologies will increase the tolerance intensity of the soil. Constitutional changes have to be introduced into the system to maintain the sustainable use of the land resources in the long run.

Following points are recommended for future studies: Adaptation of the land evaluation guidelines into the specific study areas is always on top of the task list; the exchange of the Chinese soil classification system into a FAO or USDA system, or vice versa, will greatly facilitate the progress and the accuracy of the evaluation; the automated land 
evaluation system, combined with a geographical information system, will not only improve the availability of evaluation results, but promote land evaluation to much broader users as well. The land evaluation approach in agricultural sustainability studies is an ideal field for decision support system $(D S S)$ and/or expert system $(E S)$, both in the core of modern artificial intelligence $(A I)$ theories, to apply. However, a land information database remains the first step.

\section{REFERENCES}

Brown, L. R. 1995. Who will feed China? World Watch Institute, Washington, D.C.

CAS Study Group. 1989. Survival and development (in Chinese). Science Press, Beijing.

Caoxian Office of Statistics. 1995. Statistical yearbook 1995.

Caoxian Regional Planning Office. 1986a. The integrated agricultural zonation. In: Collection of agricultural regional planning reports of Caoxian County, Shandong Province (China): 1-84.

Caoxian Regional Planning Office. 1986b. The climatic zonation. In: Collection of agricultural regional planning reports of Caoxian County, Shandong Province (China): 149-218.

Cocheme, J., Franquin, P. 1967. An agroclimatology survey of a semi-arid area in Africa, south of Sahara. World Meteorological Organization, 86, no. 210, TP 110.

Ding Shengjun. 1988. On world food issues (in Chinese). Economic Science Press, Beijing.

Doorenbos, J., Pruitt, W.O. 1977. Crop water requirements. FAO Irrigation and Drainage Paper 24, FAO, Rome, 144 pp.

Doorenbos, J., Kassam, A. H. 1979. Yield response to water. Irrigation and Drainage Paper 33, FAO, Rome, 193 pp.

Kowal, J. 1978. Agro-ecological zoning for the assessment of land potentialities for agriculture. In: Land evaluation standards for rainfed agriculture. FAO World Soil Resources Report 49, FAO, Rome.

Schultz, T. W. 1964. Transforming traditional agriculture. Yale University Press, New Haven. Chinese edition translated by X. Liang, 1987. Commercial Press, Beijing. $153 \mathrm{pp}$.

Tang, H., Ye, L. 1995. China's food production strategy for the long run: feed ourselves (in Chinese). Peasant's Daily. Nov. 21, 1995.

Tang, H., Ye, L., Zhou, Q., Van Ranst, E., Huang, X. 1997. Comparative study on methodology of land production potential (in Chinese). China Agricultural Sci-Tech Press, Beijing, 301 pp.

Van Ranst, E. 1991. Land Evaluation, Part I: Principles in Land Evaluation and Crop Production Calculations. International Training Center for Post-Graduate Soil Scientists, Ghent University, Ghent, 274 pp.

Van Ranst, E. 1997. Tropical Soils: Geograhpy, Classification, Properties and Management. Lecture notes for International Interuniversity Post-Graduate Program 
"Physical Land Resources." Laboratory of Soil Science, Ghent University, Ghent, $181 \mathrm{p}$.

WCED. 1987. Our common future. World Commission on Environment and Development. New York.

Ye, L. and Tang, H. 1996. Sustainable agriculture: the inevitable choice for Chinese agriculture in 21 century. In: Proceedings of CAAS symposium of youth scientists (in Chinese).

RECEIVED: 08/22/00

REVISED: $02 / 07 / 01$

ACCEPTED: 03/16/01

\section{For FACULTY/PROFESSIONALS with journal subscription} recommendation authority for their institutional library ... If you have read a reprint or photocopy of this article, would you like to make sure that your library also subscribes to this journal? If you have the authority to recommend subscriptions to your library, we will send you a free complete (print edition) sample copy for review with your librarian.

1. Fill out the form below and make sure that you type or write out clearly both the name of the journal and your own name and address. Or send your request via e-mail to getinfo@haworthpressinc.com including in the subject line "Sample Copy Request" and the title of this journal.

2. Make sure to include your name and complete postal mailing address as well as your institutional/agency library name in the text of your e-mail.

[Please note: we cannot mail specific journal samples, such as the issue in which a specific article appears. Sample issues are provided with the hope that you might review a possible subscription/e-subscription with your institution's librarian. There is no charge for an institution/campus-wide electronic subscription concurrent with the archival print edition subscription.]

YES! Please send me a complimentary sample of this journal:

(please write complete journal title here-do not leave blank)

I will show this journal to our institutional or agency library for a possible subscription. Institution/Agency Library:

Name:

Institution:

Address:

City:

State: Zip: 10 Alice Street, Binghamton, NY 13904-1580 